13

\title{
Особенности магнетронного напыления тонких пленок оксида никеля для применения в составе перовскитных солнечных элементов
}

\author{
(C) А.С. Агликов, ${ }^{1,2}$ Д.А. Кудряшов, ${ }^{1}$ А.М. Можаров, ${ }^{1}$ С.В. Макаров, ${ }^{2}$ А.Д. Большаков, ${ }^{1}$ И.С. Мухин ${ }^{1,2}$ \\ ${ }^{1}$ Санкт-Петербургский национальный исследовательский Академический университет РАН, \\ 194021 Санкт-Петербург, Россия \\ 2 Университет ИТМО, \\ 197101 Санкт-Петербург, Россия \\ e-mail: aglikov.aleksandr@gmail.com
}

(Поступило в Редакцию 23 июля 2018 г.)

Одним из перспективных направлений повышения эффективности перовскитных солнечных элементов является применение неорганических оксидов в качестве транспортных слоев. Приведены результаты исследования по изучению влияния состава газовой смеси плазменного разряда во время магнетронного напыления на оптические, электрические и структурные параметры осаждаемых тонких пленок оксида никеля. Показано, что при добавлении кислорода или азота к атмосфере чистого аргона (до 30\% по объему) изменяется скорость роста $(1.2-2.3 \mathrm{~nm} / \mathrm{min})$, удельное сопротивление образцов $(8.5-208 \Omega \cdot \mathrm{cm})$, ширина запрещенной зоны материала $(2.85-3.43 \mathrm{eV})$, а также спектральная зависимость коэффициента экстинкции, при близких структурных и морфологических параметрах синтезированных тонких пленок. Установлено, что самые низкие значения коэффициента экстинкции имеют пленки, осажденные в атмосфере чистого аргона, что определяет актуальность их использования в фотовольтаических преобразователях на основе перовскитных соединений.

DOI: 10.21883/JTF.2019.03.47186.290-18

\section{Введение}

С момента публикации пионерской работы [1] исследователями был признан высокий потенциал органометаллических перовскитов для использования в качестве фотоактивных слоев в солнечных элементах (СЭ). Привлекательными свойствами перовскитов являются эффективное поглощение оптического излучения, относительно большие длины свободного пробега носителей заряда, дешевизна прекурсоров для синтеза и высокая технологичность производства [2]. Эти свойства перовскитов, а также результаты многочисленных работ в данной области, позволили таким СЭ за последние семь лет продемонстрировать значительный прирост эффективности с 4 до 22\% [3], рекордный по темпам за всю историю развития солнечной энергетики.

Типичный перовскитный СЭ представляет из себя многослойную структуру, а в качестве материала фотоактивного слоя используется соединение $\left[\mathrm{CH} 3 \mathrm{NH} 3(\mathrm{MA}) \mathrm{PbX} 3\right.$, где $\mathrm{X}=\mathrm{Br}^{-}, \mathrm{Cl}^{-}, \mathrm{I}^{-}$со структурой перовскита. Этот слой заключен между дырочным и электронным транспортными слоями (hole, electron transport layer - HTL, ETL), и собирающими электродами снаружи. Важным направлением оптимизации конструкции СЭ является согласование энергетических уровней перовскита и транспортных слоев. Достижение этого согласования должно привести к повышению уровня экстракции носителей заряда из фотоактивного слоя и минимизации электрических потерь, а следовательно, к увеличению эффективности СЭ [4].
На данный момент высокие эффективности были достигнуты в планарной конфигурации СЭ с использованием в качестве дырочного проводящего слоя полимеров или низкомолекулярных соединений PEDOT:PSS, spiroOMeTAD, P3HT, PTAA [5,6]. Несмотря на высокую эффективность обсуждаемых СЭ, такие органические соединения склонны к химической нестабильности и быстрой деградации, а также обладают свойством гигроскопичности, что затрудняет растекание раствора перовскита при нанесении его из жидкой фазы при центрифугировании на подложке, увеличивая расход реагентов. Кроме того, такие соединения являются окислителями для перовскита, что приводит к ускоренной деградации фотоактивного слоя. Также было показано, что органические транспортные слои ограничивают коэффициент заполнения ВАХ и ток короткого замыкания [7].

Для реализации транспортных слоев высокого качества должны быть выполнены следующие условия: высокая прозрачность слоя в оптическом диапазоне, высокая подвижность носителей заряда по сравнению с органическими соединениями, энергетическое положение потолка валентной зоны должно быть ниже уровня HUMO (highest unoccupied molecular orbital - высшая незанятая молекулярная орбиталь) перовскита, и энергетическое положение дна зоны проводимости должно быть выше уровня LOMO (lowest occupied molecular orbital - низшая занятая молекулярная орбиталь). Альтернативой органическим соединениям могут быть неорганические полупроводниковые соединения. В работе [8] был реализован перовскитный СЭ с иодидом меди $\mathrm{CuI}$ дырочного типа проводимости в качестве HTL, который 
продемонстрировал эффективность 6\% и напряжение холостого хода на уровне $0.55 \mathrm{~V}$. Причиной низкой эффективности данного элемента, в том числе, является неудачно подобранный транспортный слой, уровень энергии дна зоны проводимости которого не согласован c LOMO-уровнем перовскита. Также в числе неорганических материалов транспортных слоев исследовались оксиды молибдена $\mathrm{MoO}_{3}$ [9] и ванадия $\mathrm{V}_{2} \mathrm{O}_{5}$ [10]. Все эти соединения по тем или иным причинам ограничивают эффективность СЭ при применении в качестве HTL.

Среди полупроводников р-типа проводимости, перспективных для применения в перовскитных СЭ, можно выделить оксид никеля $\mathrm{NiO}$ [11], который характеризуется высокой прозрачностью в оптическом диапазоне, широкой запрещенной зоной $(3.6 \mathrm{eV})$, энергетическим положением потолка валентной зоны $(-5.4 \mathrm{eV})$ и дна зоны проводимости $(-1.8 \mathrm{eV})$, химической стабильностью, что делает его перспективным кандидатом для использования с фотоактивным слоем состава $\mathrm{MAPbI}_{2} \mathrm{Br}$. В литературе сообщалось, что перовскитные СЭ со слоем оксида никеля, полученным при помощи импульсного лазерного напыления, демонстрировали эффективность $17.6 \%$ с коэффициентом заполнения 0.813 , что на настоящий момент является высоким показателем [12].

В настоящей работе исследуется влияние состава атмосферы магнетронного разряда во время осаждения пленок оксида никеля на их электрические, оптические и структурные свойства. Целью настоящей работы являлось определение оптимального состава атмосферы магнетронного разряда для получения наиболее прозрачных и проводящих слоев оксида никеля, пригодных для применения в качестве транспортных слоев в перовскитных СЭ.

\section{Экспериментальная методика}

Тонкие пленки оксида никеля были получены на стеклянных подложках толщиной $1 \mathrm{~mm}$ при помощи магнетронного напыления на установке BOC Edwards Auto 500 из мишени $\mathrm{NiO}$ чистотой $99.9 \%$ в различных атмосферах. Расстояние между мишенью и подложками составляло около $100 \mathrm{~mm}$, камера до начала процесса осаждения откачивалась до давления $1 \cdot 10^{-4} \mathrm{~Pa}$, во время плазменного разряда давление составляло $1.7 \cdot 10^{-1} \mathrm{~Pa}$. Все образцы осаждались при мощности плазменного разряда $100 \mathrm{~W}$ без подогрева подложек в течение $1 \mathrm{~h}$. В ходе работы использовались следующие составы газовой смеси: $5,15,30 \%$ азота или кислорода в смеси с аргоном, а также атмосфера чистого аргона.

Толщина пленок измерялась на профилометре Ambios XP-1, морфология поверхности (в том числе среднеквадратичная шероховатость) измерялась методом атомно-силовой микроскопии (АСМ) в полуконтактном режиме на ACM Bruker Catalyst. Спектры комбинационного (рамановского) рассеяния света (КРС)

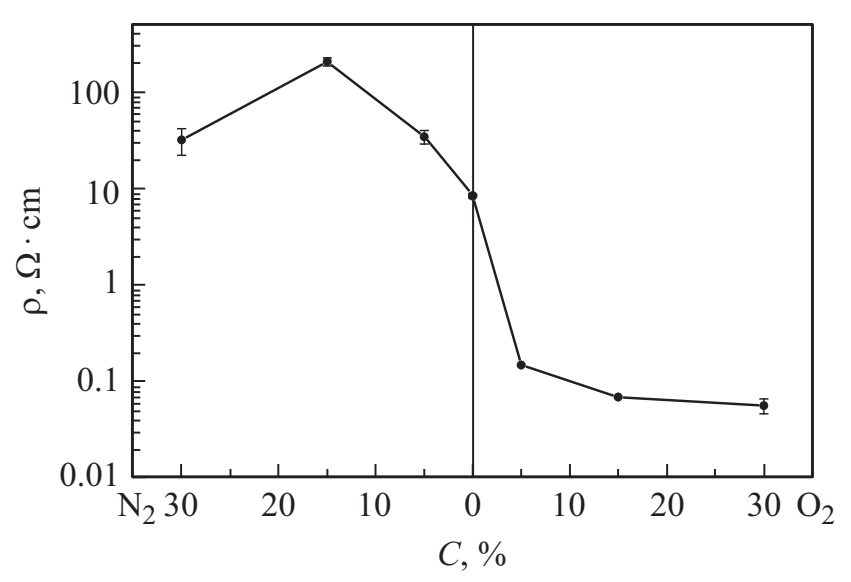

Рис. 1. Зависимость удельного сопротивления тонких пленок $\mathrm{NiO}$ от состава ростовой газовой смеси.

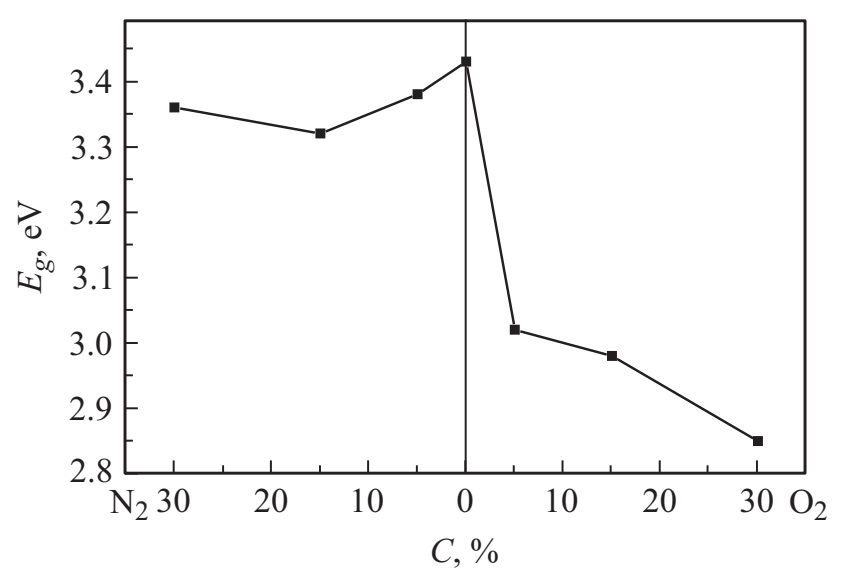

Рис. 2. Зависимость ширины запрещенной зоны тонких пленок $\mathrm{NiO}$ от состава ростовой газовой смеси.

были измерены при комнатной температуре на спектрометре Horiba LabRam HP800 при возбуждении лазером с рабочей длиной волны $\lambda=532 \mathrm{~nm}$. Возбуждение и сбор рассеянного света осуществлялись через объектив микроскопа с области поверхности образца с диаметром окружности пятна $d \approx 5-10 \mu \mathrm{m}$. В работе исследовались стоксовские компоненты КРС. Сопротивление образцов оценивалась путем измерения вольт-амперных характеристик (BAX) образцов.

\section{Результаты и обсуждение}

В первой части работы исследовалось влияние ростовой атмосферы на электрические свойства синтезируемых пленок. Для этого в эксперименте через маски напылялись образцы прямоугольной геометрии длиной $l=12 \mathrm{~mm}$ и шириной $w=3 \mathrm{~mm}$, в сущности - тонкопленочные резисторы. Далее к боковым сторонам прямоугольников были напаяны индиевые контакты. После этого измерялись ВАХ всех образцов и вычислялось сопротивление пленок $R$. Далее с учетом геометрических 
размеров контактов определялось удельное сопротивление образцов:

$$
\rho=R S / l
$$

где площадь $S$ поперечного сечения вычислялась, как произведение ширины $w$ на толщину $d$ пленки. На рис. 1 представлена зависимость удельного сопротивления тонких пленок от состава газовой смеси плазменного разряда во время осаждения. Здесь, а также на рис. 2, точки слева от оси ординат отражают данные, соответствующие пленкам, выращенным в газовой смеси аргона и азота, справа - в смеси аргона и кислорода, на оси ординат - в атмосфере чистого аргона. Согласно результатам, представленным на рис. 1, пленки, выращенные в газовой смеси азота и аргона, имеют на два порядка большее сопротивление, чем выращенные в газовой смеси кислорода и аргона, что может свидетельствовать о большой концентрации дефектов в первых.

Далее исследовались оптические характеристики пленок. Определение края полосы поглощения в диапазоне длин волн 200-400 nm позволило вычислить величину ширины запрещенной зоны образцов. На рис. 2 проиллюстрирована зависимость ширины запрещенной зоны материала синтезированных пленок от состава газовой смеси во время напыления. Из приведенных графиков видно, что пленки, выращенные в газовой смеси аргона и кислорода, обладают более широкой запрещенной зоной, чем пленки, выращенные в смеси аргона и азота. Отметим, что ожидаемая ширина запрещенной зоны $\mathrm{NiO}$, согласно [13], лежит в пределах $3.6-4 \mathrm{eV}$. Таким образом, продемонстрированы низкое удельное сопротивление пленок, выращенных в атмосфере, обогащенной кислородом, вкупе с тенденцией к уменьшению ширины запрещенной зоны, которые наиболее вероятно обусловлены их сильной нестехиометрией [13].

Низкая стехиометрия исследуемого материала обусловливается присутствием точечных дефектов в виде вакансий или междоузлий. Очевидно, в случае магнетронного напыления в присутствии кислорода велика вероятность образования междоузельных дефектов. Для оценки этой вероятности в работе [14] было показано, что энергия образования междоузельных атомов кислорода гораздо выше, чем вакансий никеля. Однако магнетронное напыление является высокоэнергетическим методом роста тонких пленок и ввиду особенностей процесса может вызывать появление междоузельных дефектов, концентрация которых была незначительна в условиях термостатического равновесия, как это было рассчитано в указанной выше работе. Таким образом, мы заключаем, что магнетронное напыление в газовой смеси аргона и кислорода может приводить к сильной нестехиометрии материала за счет появления большого числа междоузлий.

Второй важнейшей характеристикой транспортного слоя СЭ является его прозрачность. Количественной мерой поглощения света в объеме материала является

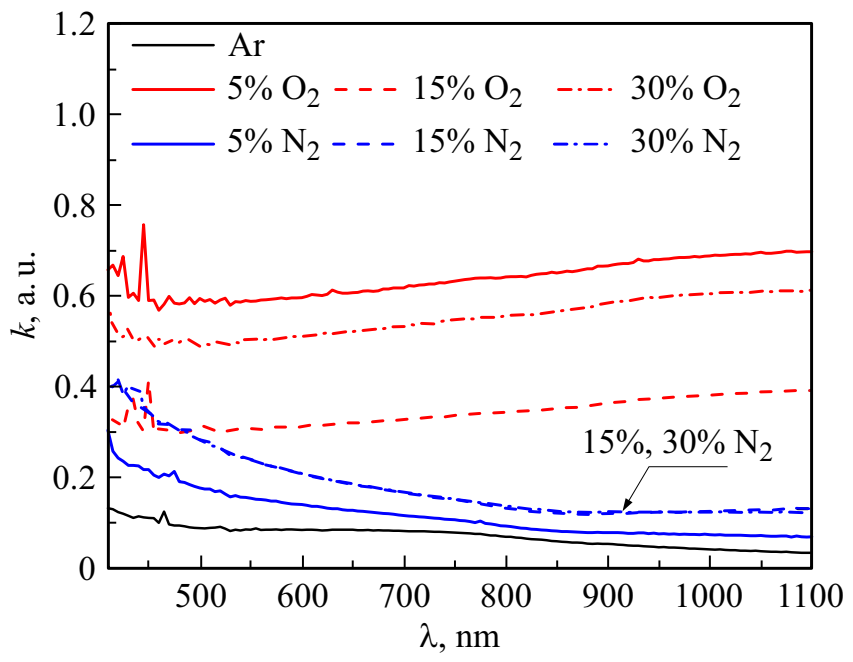

Рис. 3. Спектральная зависимость коэффициента экстинкции для тонких пленок оксида никеля.

коэффициент экстинкции. Для определения спектральной зависимости коэффициента экстинкции и оценки прозрачности пленок были измерены спектры их отражения $(R)$ и пропускания $(T)$ в видимой и ближней инфракрасной областях спектра, и, согласно закону Бугера-Ламберта, рассчитаны коэффициенты поглощения $(\alpha)$ и экстинкции $(k)$, используя следующие выражения:

$$
\begin{gathered}
T=(1-R) \exp (-\alpha d), \\
k=\alpha \lambda / 4 \pi,
\end{gathered}
$$

где $d$ - толщина пленки, $\lambda$ - длина волны падающего излучения. На рис. 3 приведены спектральные зависимости коэффициента экстинкции для пленок, синтезированных в азотной и кислородной атмосферах в сравнении с аргоновой соответственно. Для использования тонких пленок в качестве транспортных слоев в составе СЭ необходимо найти баланс между прозрачностью и электронной структурой, электрическими свойствами слоя.

Также для оценки эффективности пропускания пленок и пригодности их для использования в качестве HTL в составе СЭ, был рассчитан „интегральный коэффициент экстинкции“ (MEC - mean extinction coefficient), - отношение свертки спектров солнечного излучения $\left(S_{\text {sun }}\right)$, поглощения перовскита $\mathrm{MAPbI}_{2} \mathrm{Br}$, как прямозонного полупроводника с шириной запрещенной зоны $1.8 \mathrm{eV}$ $\left(S_{\text {perv }}\right)$, и поглощения пленок оксида никеля $(k)$ к свертке солнечного спектра и поглощения перовскита:

$$
M E C=\int\left(k S_{\text {sun }} S_{\text {perv }}\right) d \lambda / \int\left(S_{\text {sun }} S_{\text {perv }}\right) d \lambda .
$$

В таблице приведены данные по рассчитанным значениям МЕС. Коэффициент МЕС характеризует эффективность поглощения солнечного спектра пленкой оксида никеля в составе СЭ. Самыми прозрачными для данной свертки оказались пленки, полученные в атмосфере 
Значения скорости роста, шероховатости, удельного сопротивления, ширины запрещенной зоны и интегрального коэффициента экстинкции (ИКЭ) пленок

\begin{tabular}{|c|c|c|c|c|c|c|}
\hline № & Атмосфера & $\begin{array}{c}\text { Скорость роста, } \\
\mathrm{nm} / \mathrm{min}\end{array}$ & $\begin{array}{c}\text { СКО шероховатость, } \\
\mathrm{nm}\end{array}$ & $\begin{array}{c}\text { Уд. сопротивление, } \\
\Omega \cdot \mathrm{cm}(\text { надежность } 0.95)\end{array}$ & $\begin{array}{c}\text { Ширина запрещенной } \\
\text { зоны, eV }\end{array}$ & MEC. a.u. \\
\hline 1 & $30 \% \mathrm{~N}_{2}: 70 \% \mathrm{Ar}$ & 2.34 & 1.46 & $31.27 \pm 9.88$ & 3.36 & 0.205 \\
\hline 2 & $15 \% \mathrm{~N}_{2}: 85 \% \mathrm{Ar}$ & 2.05 & 0.87 & $207.87 \pm 20.11$ & 3.31 & 0.203 \\
\hline 3 & $5 \% \mathrm{~N}_{2}: 95 \% \mathrm{Ar}$ & 2.17 & 1.31 & $34.81 \pm 5.56$ & 3.39 & 0.134 \\
\hline 4 & $100 \% \mathrm{Ar}$ & 2.55 & 0.85 & $8.48 \pm 0.31$ & 3.43 & 0.082 \\
\hline 5 & $5 \% \mathrm{O}_{2}: 95 \% \mathrm{Ar}$ & 1.47 & 0.93 & $(150.51 \pm 3.91) \cdot 10^{-3}$ & 3.02 & 0.618 \\
\hline 6 & $15 \% \mathrm{O}_{2}: 85 \% \mathrm{Ar}$ & 1.34 & 0.99 & $(70.16 \pm 1.51) \cdot 10^{-3}$ & 2.97 & 0.326 \\
\hline 7 & $30 \% \mathrm{O}_{2}: 70 \% \mathrm{Ar}$ & 1.17 & 1.03 & $(57.61 \pm 10.01) \cdot 10^{-3}$ & 2.85 & 0.528 \\
\hline
\end{tabular}

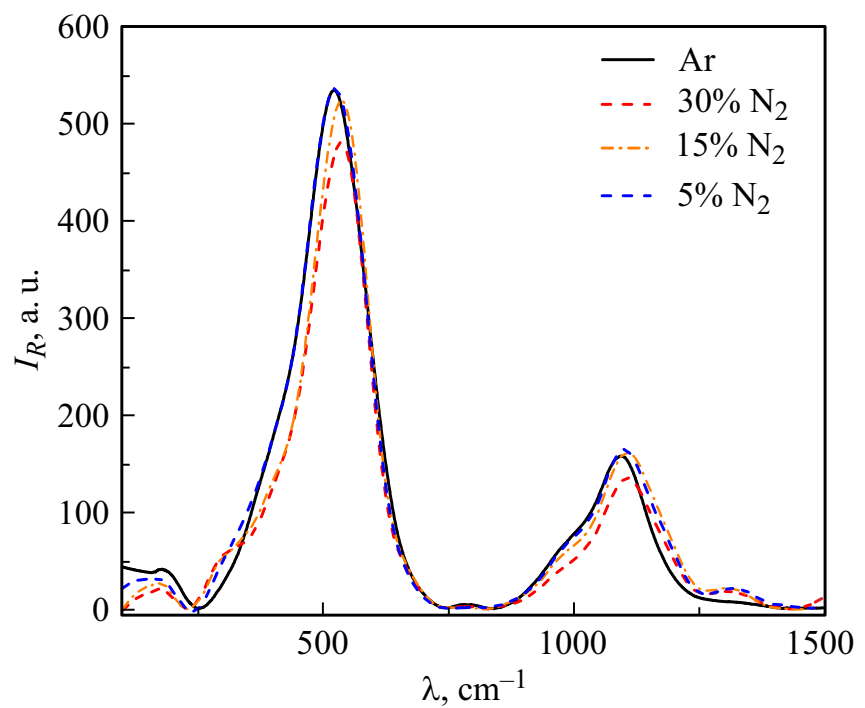

Рис. 4. Спектр комбинационного рассеяния для тонких пленок, напыленных в газовой смеси азота и аргона.

чистого аргона: интегральный коэффициент экстинкции составил 0.082. Наибольшее значение МЕC - 0.618 обнаружено в пленке, выращенной в атмосфере состава 95\% Ar: 5\% О 2 . Кислородные пленки гораздо интенсивнее поглощают излучение в диапазоне измерений, что говорит о высокой концентрации дефектов в них.

Для качественной оценки фазового состава и кристаллического совершенства пленок были измерены спектры комбинационного рассеяния света (КРС), приведенные на рис. 4 и 5. Известно, что вследствие симметрийных соображений для монокристаллов $\mathrm{NiO}$ в парамагнитной фазе $\left(T>T_{\text {Neel }}\right)$, оптические фононные моды первого порядка не активны, а в спектрах КРС наблюдаются лишь полосы более высоких порядков, связанные образованием или поглощением двух и более оптических фононов [15]. В то же время для полученных пленок $\mathrm{NiO}$ в спектрах КРС наблюдается активная полоса со стоксовским сдвигом в $400-600 \mathrm{~cm}^{-1}$, соответству-

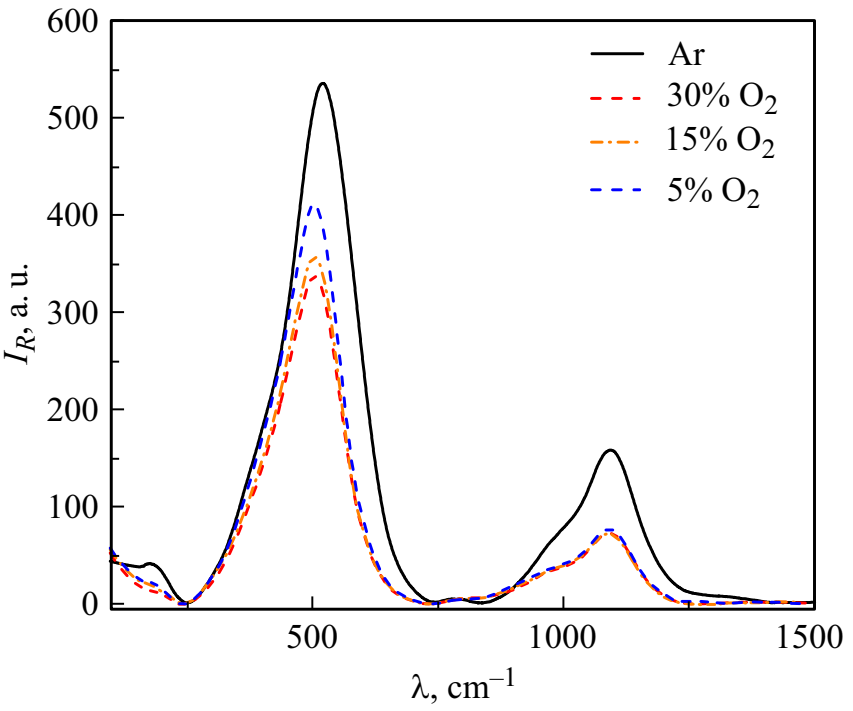

Рис. 5. Спектр комбинационного рассеяния для тонких пленок, напыленных в газовой смеси кислорода и аргона.

ющая, согласно литературным данным, однофононной поперечной $\left(\approx 550 \mathrm{~cm}^{-1}\right)$ и продольной $\left(\approx 400 \mathrm{~cm}^{-1}\right)$ оптическим модам (ТO - transvers optical, LO longitudinal optical). Однофононное КРС в $\mathrm{NiO}$ может наблюдаться как при понижении симметрии при магнитном упорядочении (температура Нееля для $\mathrm{NiO}$ $\left.T_{\mathrm{N}}=650 \mathrm{~K}[16]\right)$, так и в случае нарушения симметрии, связанного с микрокристаллической структурой пленок. Наиболее вероятно, что синтезированные пленки являются магнитно-неупорядоченными, так как в спектрах КРС отсутствует полоса, соответствующая двухмагнонному рассеянию $\left(\approx 1500 \mathrm{~cm}^{-1}\right)$ [16]. Интенсивность КРС первого порядка в несколько раз превышает интенсивность двухфононных полос, соответствующих образованию пар ТО + LO фононов $\left(\approx 900 \mathrm{~cm}^{-1}\right)$ и 2LO фононов $\left(\approx 1090 \mathrm{~cm}^{-1}\right)$ [16]. Взаимная интенсивность пиков от пленки к пленке немного изменяется, сдвиг фононных полос по энергии может быть связан 
с изменением параметра решетки при отклонении от стехиометрического состава. В целом положение и относительная интенсивность фононных полос согласуется с литературными данными для микрокристаллического или наноструктурированного $\mathrm{NiO}_{x}[17]$. Полоса, соответствующая однофононной моде КРС, сильно уширена, что, согласно литературе [18], коррелирует с большим количеством дефектов кристаллической решетки и/или наличием поверхностных эффектов, что характерно для микрокристаллов $\mathrm{NiO}_{x}$. Таким образом, наблюдаемые интенсивные уширенные полосы КРС первого порядка свидетельствуют о микрокристаллической структуре синтезированных пленок. Отсутствие других линий в спектрах КРС свидетельствует об однородности фазового состава пленок.

Также с помощью АСМ была проведена оценка шероховатости поверхности. В таблице приведены значения среднеквадратичных шероховатостей для всех образцов. Шероховатости синтезированных пленок отличаются друг от друга не более чем на $0.5 \mathrm{~nm}$. Отметим, что поверхности имеют низкую шероховатость, среднеквадратичное значение которой лежит в интервале 0.85-1.46 nm. Гладкость поверхности осажденных пленок позволяет обеспечить качественное нанесение на них растворов перовскитов.

Для систематизации результатов работы в таблице приведены значения измеренных и рассчитанных в ходе работы величин для пленок $\mathrm{NiO}$, полученных при различных технологических параметрах процесса магнетронного распыления: скорость роста, величина среднеквадратичной шероховатости, удельное сопротивление, ширина запрещенной зоны и интегральный коэффициент экстинкции.

\section{Заключение}

В ходе работы с помощью магнетронного напыления были выращены тонкие пленки оксида никеля в различных атмосферах плазменного разряда. Было показано, что состав атмосферы плазменного разряда существенно влияет на свойства образцов. Наилучшей проводимости пленок удалось достичь при разбавлении аргона кислородом. Ширина запрещенной зоны материала варьировала в широком диапазоне и имела минимальное значение $2.85 \mathrm{eV}$ при концентрации кислорода 30\%. Максимальное значение этого параметра зафиксировано в чистом аргоне и составило $3.43 \mathrm{eV}$. Наиболее прозрачные пленки были изготовлены в атмосфере чистого аргона, а наименее прозрачные и наиболее проводящие - в смеси кислорода и аргона. Оптимизация методов осаждения пленок оксида никеля была направлена на создание эффективных СЭ на основе перовскитов состава $\mathrm{MAPbI}_{2} \mathrm{Br}$ с параметрами энергетических уровней HUMO: $-5.4 \mathrm{eV}$ и LOMO: $-3.6 \mathrm{eV}$. Результаты работы показывают, что наиболее перспективными тонкими пленками оксида никеля для их использования в качестве HTL в CЭ пред- ставляются пленки, напыленные в атмосфере чистого аргона.

Авторы выражают искреннюю благодарность В.В. Федорову и Г.А. Сапунову (СПбАУ РАН) за помощь в интерпретации спектров КРС. Исследование было поддержано грантом РФФИ № 18-32-00899, а также грантами президента РФ МК-6492.2018.2, МК-3632.2017.2, грантами правительства РФ (гос. задание) № 3.9796.2017/8.9, 16.2593.2017/4.6 и № 16.8939.2017/8.9.

\section{Список литературы}

[1] Akihiro Kojima et al. // J. American Chem. Society. 2009. Vol. 131. N 17. P. 6050-6051.

[2] Chen Q., Zhou H., Hong Z., Luo S., Duan H.-S., Wang H.-H., Liu Y., Li G., Yang Y. // J. Am. Chem. Soc. 2014. Vol. 136. P. 622.

[3] Woon Seok Yang, Byung-Wook Park, Eui Hyuk Jung, Nam Joong Jeon, Young Chan Kim, Dong Uk Lee, Seong Sik Shin, Jangwon Seo, Eun Kyu Kim, Jun Hong Noh, Sang Il Seok // Science. 2017. Vol. 356. N 6345. P. 1376.

[4] Edri E., Kirmayer S., Kulbak M., Hodes G., Cahen D. // J. Phys. Chem. Lett. 2014. Vol. 5. P. 429.

[5] Wang J., Wang S., Li X., Zhu L., Meng Q., Xiao Y., Li D. // Chem. Commun. 2014. Vol. 50. P. 5829.

[6] Krishnamoorthy T., Kunwu F., Boix P., Li H. // J. Mater. Chem. A. 2014. Vol. 2. P. 6305.

[7] Jeng J.Y., Chiang Y.F., Lee M.H., Peng S.R., Guo T.F., Chen P., Wen T.-C. // Adv. Mater. 2013. N 25. P. 3727.

[8] Wang K.-C., Jeng J.-Y., Shen P.-S., Chang Y.-C., Diau E.W.G., Tsai C.-H., Chao T.-Y., Hsu H.-C., Lin P.-Y., Chen P., Guo T.-F., Wen T.-C. // Sci. Rep. 2014. Vol. 4. P. 4756.

[9] Kee Eun Lee, Lijia Liu, Timothy L. Kelly // J. Phys. Chem. C. 2014. Vol. 118. N 48. P. 27735-27741.

[10] Xinchen Li, Fengxian Xie, Shaoqing Zhang, Jianhui Hou, Wallace CH Choy // Light: Sci. Appl. 2015. Vol. 4. P. 273.

[11] Park J.H., Seo J., Park S., Shin S.S., Kim Y.C., Jeon N.J., Shin H.W., Ahn T.K., Noh J.H., Yoon S.C. // Adv. Mater. 2015. Vol. 27. P. 4013.

[12] Wang K.-C., Jeng J.-Y., Shen P.-S., Chang Y.-C., Diau E.W.G., Tsai C.-H., Chao T.-Y., Hsu H.-C., Lin P.-Y., Chen P., Guo T.-F., Wen T.-C. // Sci. Rep. 2014. Vol. 4. P. 4756.

[13] Grilli M.L., Menchini F., Dikonimos T., Nunziante P., Pilloni L., Yilmaz M., Piegari A., Mittiga A. // Sci. Technol. 2016. Vol. 31. P. 055016.

[14] Lany S., Osorio-Guillén J., Zunger A. // Phys. Rev. B. 2007. Vol. 75. P. 241203

[15] Polarisation dependent Raman study of single-crystal nickel oxide Cent. Eur. // J. Phys. 2011. 9 (4). P. 1096-1099. DOI: $10.2478 / \mathrm{s} 11534-010-0130-9$

[16] Dietz R.E., Parisot G.I., Meixner A. E. // Phys. Rev. B. 1971. Vol. 4. N 7.

[17] Anandan K., Rajendran V. // Mater. Sci. Semicond. Proc. 2011. Vol. 14. P. 43.

[18] Kaviyarasu K., Manikandan E., Kennedy J., Jayachandran M. // Mater. Lett. 2014. Vol. 120. P. 243-245. 